\title{
The Effect of Growth and Urea Concentration on Ammonia Production by a Urea-hydrolysing Mycoplasma (Ureaplasma urealyticum)
}

\author{
By GERALD K. MASOVER,* JOHN CATLIN AND \\ LEONARD HAYFLICK \\ Department of Medical Microbiology, Stanford University School of Medicine, \\ Stanford, California 94305, U.S.A.
}

(Received 30 July 1976; revised 2 November 1976)

\begin{abstract}
SUMMARY
The rate of accumulation of ammonium ion in cultures of Ureaplasma urealyticum was independent of the growth rate and of the initial urea concentration above $0.025 \%$ in the medium, although the quantity of ammonium ion accumulating did depend on the initial urea concentration. Ammonium ions accumulated at a similar rate in $U$. urealyticum cultures of both rapidly and slowly growing organisms. Viable but non-growing ureaplasmas also produced ammonia in complete medium at a lower temperature than usual $\left(25^{\circ} \mathrm{C}\right)$ or in an inadequate growth medium at $37^{\circ} \mathrm{C}$. The rate of ammonium ion accumulation in a dying culture depended on the number of viable organisms present; this is relevant to diagnostic methods for ureaplasmas which depend on detecting ammonia colorimetrically.
\end{abstract}

\section{INTRODUCTION}

The urea-hydrolysing capability of ureaplasmas (formerly T-strain mycoplasmas) differentiates them from all other members of the class Mollicutes (Shepard et al., 1974). Recent evidence (Masover \& Hayflick, 1973; Masover \& Hayflick, 1974; Masover, Benson \& Hayflick, 1974) suggests that ureaplasmas, like other urease-positive organisms, can multiply in the absence of urea. If this is true, then the enzyme responsible for urea hydrolysis in ureaplasmas may provide a way to study regulation and genetics in mycoplasmas. Hitherto, this has been difficult or impossible because metabolic functions not essential for survival of these organisms have not yet been elucidated and stable mutants have not yet been found.

The production of ammonia by hydrolysis of urea is of practical importance, however, because the alkaline $\mathrm{pH}$ change in growth media containing urea may be visualized by including a $\mathrm{pH}$ indicator in the medium. This property of ureaplasmas has direct diagnostic value (Shepard, 1973) and is also used in assessing antibodies against the organisms by metabolic inhibition testing (Purcell et al., 1966; Black, 1973; Lin \& Kass, 1970).

We have examined ammonia production in cultures of Ureaplasma urealyticum as a function of the growth rate and initial urea concentration in the medium in order to better understand this aspect of ureaplasma urease activity.

* Present address: Department of Surgery, Division of Urology, S-287, Stanford University School of Medicine, Stanford, California 94305, U.S.A. 


\section{METHODS}

Ureaplasmas. The strain used was Ureaplasma urealyticum (formerly T-strain 960) which had been cloned eight times and supplied originally by Maurice Shepard (Camp Lejeune, North Carolina, U.S.A.). The organisms have been grown in our laboratory for several years and have been passaged in medium without added urea (Masover \& Hayflick, 1973). Exponentially growing stocks in the test medium, i.e. broth medium containing $10 \%(\mathrm{v} / \mathrm{v})$ dialysed calf serum and $0.025 \%(\mathrm{w} / \mathrm{v})$ urea, were always used and were usually inoculated into the medium at $\mathrm{I} \%(\mathrm{v} / \mathrm{v})$. For inoculation into medium unable to support growth, such as Basal Medium Eagle (BME) or MES buffer (see below), the growing stocks were harvested by centrifuging at $\mathrm{I} 8000 \mathrm{~g}$ for $\mathrm{I} 5 \mathrm{~min}$, washed by centrifugation and resuspension, and finally resuspended in the media.

Media and growth conditions. Urea medium for growing $U$. urealyticum has been described previously (Masover \& Hayflick, 1973; Masover et al., 1974). This medium was also used for ureaplasma quantitation as described below. In most experiments, the horse serum component of the medium was replaced by dialysed calf serum (Microbiological Associates, Bethesda, Maryland, U.S.A.). Other experimental media are described in the text.

Viable counts. The ureaplasmas were counted by a modification of the tube dilution method used for determination of colour change units (c.c.u.) (Purcell et al., 1966). A $\mathrm{I} \cdot 0 \mathrm{ml}$ sample of ureaplasma broth culture was diluted IO-fold serially in urea $(0 . \mathrm{I} \%)$ medium. Each dilution was then divided into six lots of $1.5 \mathrm{ml}$, and after 5 days incubation the colour change endpoint was calculated by the method of Reed \& Muench (1938) and expressed as c.c.u. ${ }_{50} \mathrm{ml}^{-1}$.

Ammonia analysis. Ammonia was determined by the microdiffusion and Nesslerization method of Seligson \& Seligson (195I).

Reagents. $N$-2-Hydroxyethylpiperazine- $N^{\prime}$-2-ethanesulphonic acid (HEPES) and 2- $(N$ morpholino)ethanesulphonic acid hydrate (MES) were from Calbiochem. Nessler reagent, in dry form (item no. R-496P), was from Hellige, Garden City, New York, U.S.A., and prepared according to manufacturer's instructions.

\section{RESULTS}

Lowering the incubation temperature from $37 \pm \mathrm{I}{ }^{\circ} \mathrm{C}$ to $28 \pm \mathrm{I}{ }^{\circ} \mathrm{C}$ decreased the multiplication rate of the organisms in a broth medium containing $0.1 \%(w / v)$ urea from about $3 \mathrm{~h}$ to about $6 \mathrm{~h}$ (Fig. I $a$ ). If the temperature was lowered to $25 \pm \mathrm{I}{ }^{\circ} \mathrm{C}$ the organisms did not multiply but did remain viable (Fig. 4). Urea hydrolysis, assessed by the release of ${ }^{14} \mathrm{CO}_{2}$ from $\left[{ }^{14} \mathrm{C}\right]$ urea and ammonia accumulation, was observed at all these temperatures. Experiments at the lower temperatures had the advantage of slowing down ammonia accumulation and the resulting $\mathrm{pH}$ change so that these changes and their relationship to each other could be assessed more critically.

Ureaplasma urealyticum growing at $28^{\circ} \mathrm{C}$ in a medium containing $10 \%(\mathrm{v} / \mathrm{v})$ unheated whole horse serum and $0 . \mathrm{I} \%(\mathrm{w} / \mathrm{v})$ added urea had a doubling time between 6 and $7 \mathrm{~h}$ (Fig. I $a$ ). Medium prepared with dialysed calf serum instead of horse serum and with $0.025 \%(\mathrm{w} / \mathrm{v})$ urea facilitated control of the initial amount of urea added and did not alter the growth rate compared with that in horse serum (Fig. $\mathrm{I} b$ ). The rate of ammonia accumulation under these conditions (Fig. I $b$ ) was approximately $4^{\cdot} \circ \mu \mathrm{g} \mathrm{NH}_{4}{ }^{+} \mathrm{h}^{-1}\left(\mathrm{IO}^{6} \text { c.c.u }{ }_{\cdot 50}\right)^{-1}$. Thus, the use of horse serum and different initial concentrations of urea did not affect the 


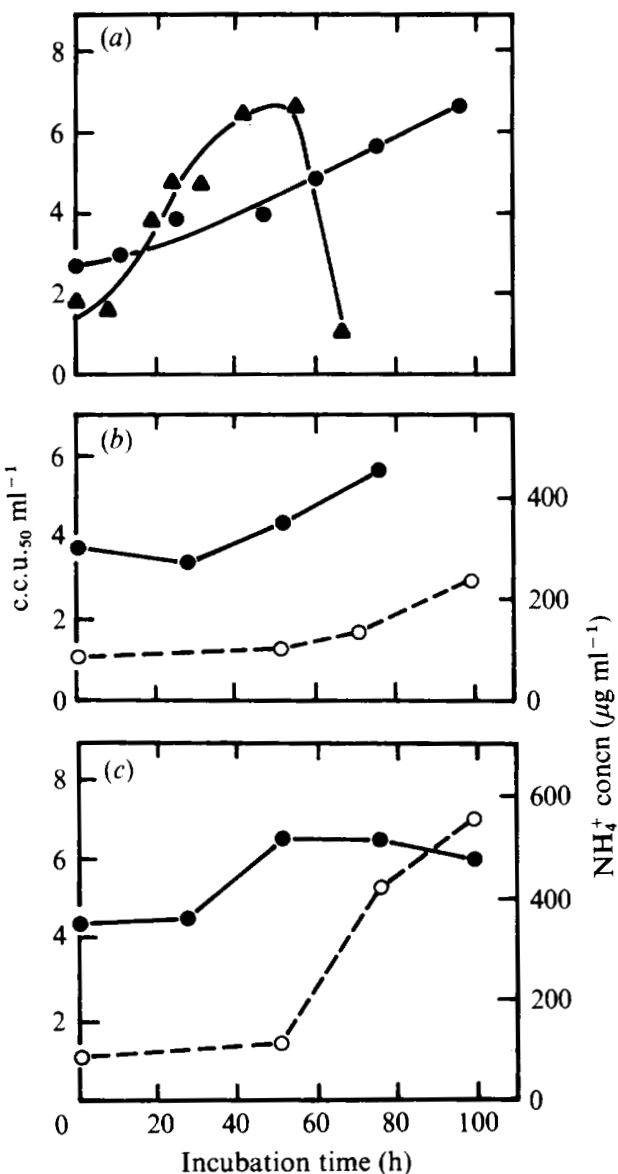

Fig. I
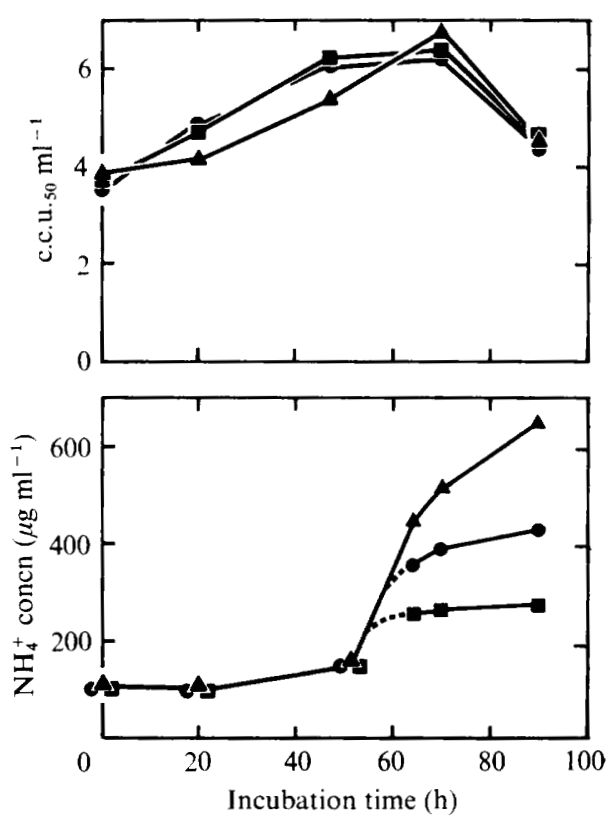

Fig. 2

Fig. I. Growth at $37{ }^{\circ} \mathrm{C}(\Delta)$ and $28^{\circ} \mathrm{C}(\mathbf{O})$ and ammonium ion accumulation $(O)$ in cultures of U. urealyticum in broth medium containing: $(a) 0.1 \%(\mathrm{w} / \mathrm{v})$ urea plus $10 \%(\mathrm{v} / \mathrm{v})$ horse serum; $(b)$ $0.025 \%(\mathrm{w} / \mathrm{v})$ urea plus $10 \%(\mathrm{v} / \mathrm{v})$ dialysed calf serum; $(c) 0.1 \%(\mathrm{w} / \mathrm{v})$ urea plus $10 \%(\mathrm{v} / \mathrm{v})$ horse serum.

Fig. 2. Growth and ammonium ion accumulation in cultures of $U$. urealyticum incubated at $28^{\circ} \mathrm{C}$. Dashed lines represent the expected ammonium ion accumulation if it is assumed that the initial rates of accumulation are the same for the three initial urea concentrations tested (see text). Initial urea concentrations $(\%, w / v): \Delta, 0 . \mathrm{I} ; \boldsymbol{O}, 0.05 ; \boldsymbol{\square}, 0.025$.

growth rate or the rate of ammonia accumulation at $28^{\circ} \mathrm{C}$. Therefore, in most of the experiments, dialysed calf serum was used in those media which contained serum.

An unexpected and unexplained observation was the prolonged stationary phase at a titre about $10^{6}$ c.c.u.$_{50} \mathrm{ml}^{-1}$ (Fig. I c) at $28^{\circ} \mathrm{C}$, despite high $\mathrm{pH}$ and ammonia concentration. This suggests that a temperature-sensitive process might be involved in the rapid death of ureaplasma cultures grown in medium containing urea at $37^{\circ} \mathrm{C}$ (Fig. I $\mathrm{a}$ ). If this is true, the same process is not involved in prevention of higher titres. Possibly, though, rapid death and low titres of ureaplasmas are unrelated.

The initial urea concentration made little difference to the rates of ammonia accumulation and growth at $28{ }^{\circ} \mathrm{C}$ (Fig. 2). The final amount of ammonia which accumulated, however, was related to the initial urea concentration and was similar to amounts observed 


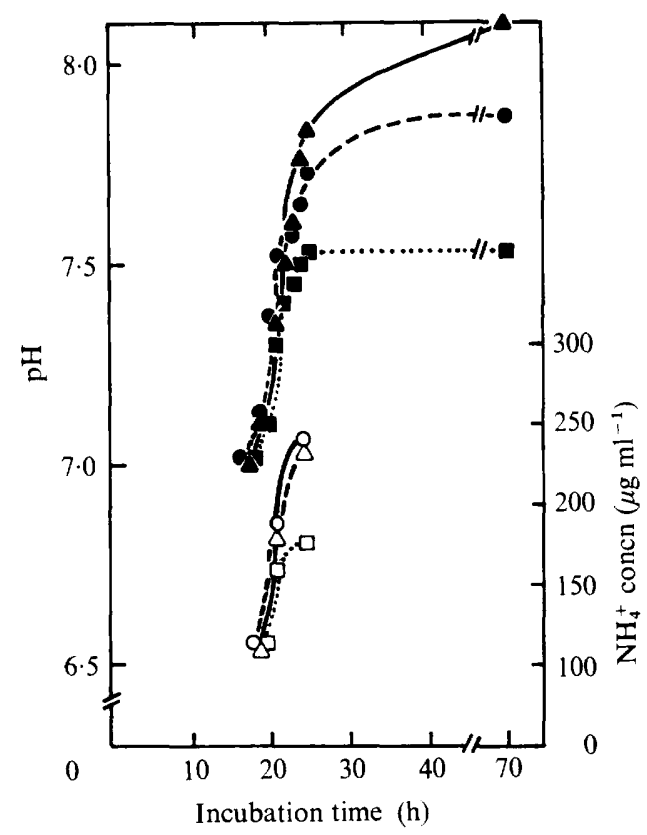

Fig. 3

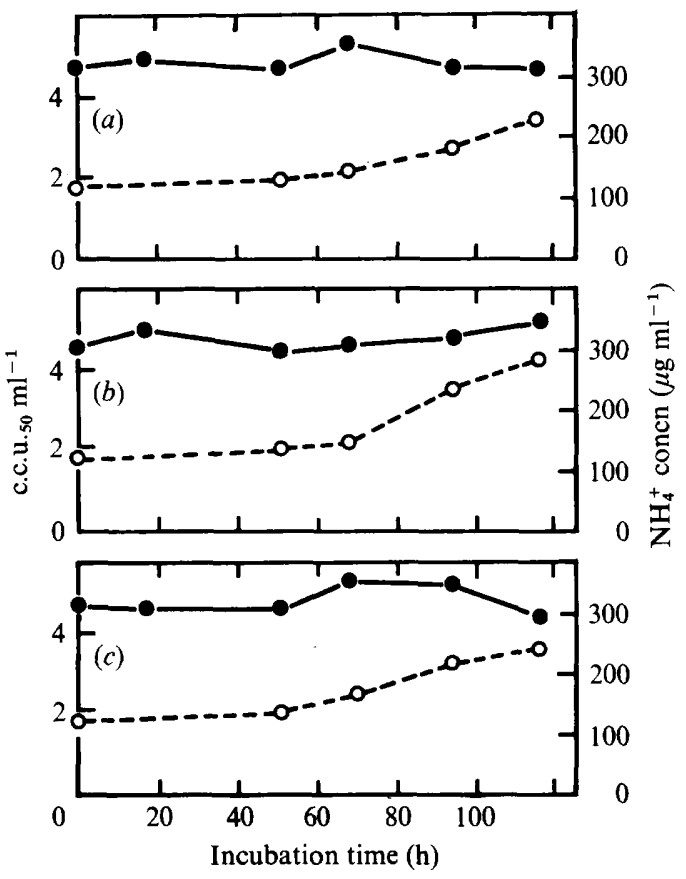

Fig. 4

Fig. 3. Accumulation of ammonium ion and pH changes in cultures of $U$. urealyticum grown in media containing different initial urea concentrations and incubated at $37^{\circ} \mathrm{C}$. Closed symbols, $\mathrm{pH}$; open symbols, ammonium ion concentration; symbols for urea concentration as in Fig. 2 legend.

Fig. 4. Growth (O) and ammonium ion accumulation $(O)$ in cultures of $U$. urealyticum incubated at $25{ }^{\circ} \mathrm{C}$ in media containing different initial urea concentrations $(\%, w / v):(a) 0.1 ;(b) 0.05 ;(c)$ 0.025 .

at higher incubation temperatures (Masover et al., I974; Ford \& MacDonald, 1967). The final amount of ammonia accumulated as a result of growth of the ureaplasmas in media with lower initial urea concentrations $(0.025 \%$ and $0.05 \%)$ was about $25 \mu \mathrm{g} \mathrm{ml}^{-1}$ more than would be expected from the total hydrolysis of the added urea. This has been observed and reported previously (Masover \& Hayflick, I974) for dialysing cultures of ureaplasmas and suggests the presence of more than one ammonia-producing metabolic process. Our previous estimate of the $K_{\mathrm{m}}$ for urea hydrolysis (Masover, Sawyer \& Hayflick, 1976; Swanberg, Masover \& Hayflick, unpublished) was between I and $2.8 \mathrm{~mm}$ which suggests that the initial rates of ammonia production from urea at $0.025 \%(4.25 \mathrm{~mm})$ or greater should be about the same. To verify this, measurements were made when, and shortly after, ammonia began to accumulate (Fig. 3) by recording the rise in $\mathrm{pH}$ of the medium, which is closely related to the ammonia concentration (Masover \& Hayflick, 1974; Masover et al., 1974). This was done by preparing several twofold dilutions of the same culture in sterile medium containing urea so that the $\mathrm{pH}$ of the resultant cultures at slightly different stages with respect to the number of organisms per volume of medium could be measured simultaneously. In this manner, it was possible to observe the short period during which most of the changes occurred. The initial rates of ammonia accumulation were the same for all three initial urea concentrations indicating that all these concentrations are near or above the minimum concentration required for the maximum rate of urea hydrolysis. 


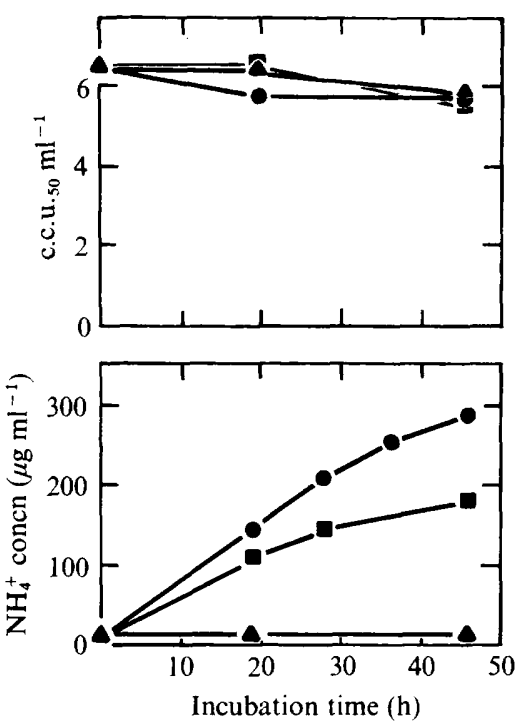

Fig. 5
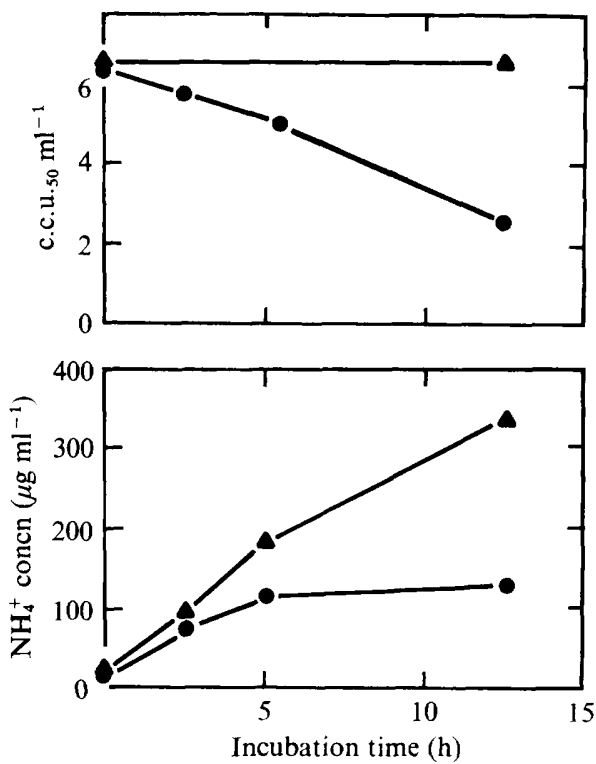

Fig. 6

Fig. 5. Ammonium ion accumulation in non-growing cultures of $U$. urealyticum. Ureaplasmas growing at $28^{\circ} \mathrm{C}$ were removed from the growth medium by centrifugation, washed once in BME, and then resuspended in a volume of BME plus $28 \mathrm{mM}$-HEPES equal to the volume of the initial culture. The BME was unsupplemented $(\boldsymbol{\Delta})$ or supplemented with $0.025 \%(\mathrm{w} / \mathrm{v})$ urea $(\boldsymbol{\square})$, or $0.05 \%(\mathrm{w} / \mathrm{v})$ urea $(\mathbf{O})$, and incubated at $28^{\circ} \mathrm{C}$.

Fig. 6. Growth and ammonium ion accumulation in cultures of $U$. urealyticum. Stocks growing at 35 to $37^{\circ} \mathrm{C}$ were harvested and washed as described in Fig. 5 legend. The organisms were then resuspended in either BME plus $28 \mathrm{mM}-\mathrm{HEPES}(\boldsymbol{\Delta})$ or $50 \mathrm{mM}-\mathrm{MES}(\boldsymbol{O})$ ). Both media contained $0.05 \%(w / v)$ urea final concentration.

Measurements of growth and ammonia accumulation in complete medium containing the three different initial urea concentrations at $25^{\circ} \mathrm{C}$ (Fig. 4) showed that the organisms were not multiplying. This was also observed (not shown) for several lower initial titres. Ammonia, however, continued to accumulate in all cases at a rate and extent that was independent of the initial urea concentration, similar to what was observed in growing cultures. The rate of ammonia production was estimated as $\mathrm{I} 5$ to $20 \mu \mathrm{g} \mathrm{NH}_{4}{ }^{+} \mathrm{h}^{-1}\left(\mathrm{IO}^{6} \text { c.c.u. }{ }_{50}\right)^{-1}$ in reasonable agreement with that obtained at $28{ }^{\circ} \mathrm{C}$ and with the amounts previously observed in cultures growing at $34{ }^{\circ} \mathrm{C}$ (Masover \& Hayflick, I974; Masover et al., 1974). Although urea depletion was not measured, the ability of the organism to hydrolyse urea was observed at $25^{\circ} \mathrm{C}$ and at the other temperatures studied. Thus, viable but non-growing ureaplasmas in complete growth medium produced ammonia (presumably from urea) at a rate that was independent of the initial urea concentration. Although the final amount of ammonia was not measured in this experiment, it would be expected to be similar to that observed in Fig. 2 but after a much longer period of time. In viable but non-growing ureaplasmas, the accumulation of ammonia would be expected to be linear and continuous from the beginning of the experiment until the substrate is sufficiently depleted but this was not observed: a delay was apparent before ammonia began to accumulate (Fig. 4). We cannot as yet explain this observation.

This type of delay did not occur in a similar experiment using ureaplasmas which could not multiply because they were in an inadequate growth medium although urea was present 
(Fig. 5). In this case, the organisms used were harvested from our usual medium by centrifuging, washed in BME and resuspended in BME plus urea and $28 \mathrm{mM}-\mathrm{HEPES}$ buffer at an initial titre above ${ }_{10} 0^{6}$ c.c. u. $_{50} \mathrm{ml}^{-1}$. The conclusions drawn were: (i) the cells were viable in BME for the period studied; (ii) the rate and extent of ammonia accumulation were independent of growth but were related to the initial urea concentration; (iii) there was no detectable change in the ammonia concentration in BME without added urea, suggesting that the ammonia produced in the other experimental media was derived from added urea, and also that no component of BME is directly, metabolically converted to ammonia in these conditions; and (iv) viability of non-growing ureaplasmas at $28{ }^{\circ} \mathrm{C}$ in $\mathrm{BME}$ plus urea is unaffected, suggesting that if a toxic factor is produced by these organisms (Furness, I973), it is unrelated to urea hydrolysis in non-growing organisms.

As ammonia accumulated in growing and non-growing cultures of ureaplasma, we also assessed if it did so during the death phase of a culture. Using MES buffer, which when used alone at $50 \mathrm{~mm}$ is toxic to the ureaplasmas (unpublished work), our results (Fig. 6) suggested that the production of ammonia was related to the number of viable organisms which remained.

\section{DISCUSSION}

A number of diagnostic test procedures and media have been developed to identify ureaplasmas; these are based on their urease activity which results in the production of ammonia and a change in the $\mathrm{pH}$ of the growth environment, demonstrated using $\mathrm{pH}$ indicators. The specificity of such diagnostic procedures depends on their ability to select the organism being diagnosed from among diverse organisms in the sample, and the sensitivity of a diagnostic test depends, as do many microbiological diagnoses, on enrichment for the selected species. This at least implies a relationship between the diagnostic character being tested and the growth and viability of the cells. Since the underlying function of ureases is uncertain, we do not really know if a cell must be viable to hydrolyse urea. There is, in fact, evidence to the contrary (Ford \& MacDonald, 1967; Masover, Razin \& Hayflick, unpublished). In the absence of a relationship between cell viability and urease activity, any preponderance of alkali-producing reactions over acid-producing ones would provide a false positive result depending on the buffering capabilities of the medium being used.

We have studied the production of ammonia by $U$. urealyticum as a function of growth and of the initial urea concentration in the medium, since these are the factors which ultimately relate to ureaplasma diagnosis. Several conclusions can be drawn. The major one is that the accumulation of ammonia by ureaplasmas depends on the initial concentration of urea in the medium but not on the rate of growth of the organisms. At non-limiting urea concentrations, ammonia accumulates at a rate which appears to relate to the number of viable cells present whether or not the cells (taken as a population) are increasing in number. Inhibition of urea metabolism is thus unrelated to inhibition of growth. The observation (Masover, Razin \& Hayflick, unpublished) that urease activity may continue for many hours after the cells are no longer viable may help a diagnosis but its value in serology must be assessed with caution. Possibly the urease is active in intact non-viable cells but is lost when the cells are lysed, as we have found urease activity in non-viable ureaplasmas separated from growth medium by filtration (Masover, Razin \& Hayflick, unpublished), though we have not yet extensively tested the relationship between lysis of ureaplasmas and urease activity. At present, inclusion of lytic factors, such as complement, in serological tests which depend on ammonium formation is recommended for the best results (Shepard et al., I974; Black, I973; Lin \& Kass, 1970; Purcell et al., I966). 
The authors gratefully acknowledge the technical assistance of Laura Cameron. This work was supported by Public Health Service Grant AI I 805 from the National Institute of Allergy and Infectious Diseases, National Institutes of Health, Bethesda, Maryland.

\section{REFERENCES}

BLACK, F. T. (1973). Modifications of the growth inhibition test and its application to human T-mycoplasmas. Applied Microbiology 25, 528-533.

ForD, D. K. \& MACDonaLD, J. (1967). Influence of urea on the growth of T-strain mycoplasmas. Journal of Bacteriology 93, I 509-I 5 I2.

Furness, G. (1973). T-mycoplasmas: their growth and production of a toxic substance in broth. Journal of Infectious Diseases 127, 9-16.

LIN, J-S., \& KASS, E. H. (I970). Immune inactivation of T-strain mycoplasmas. Journal of Infectious Diseases 122, 93-95.

MASOVER, G. K. \& HAYFLICK, L. (I973). Growth of a T-strain mycoplasma in medium without added urea. Annals of the New York Academy of Sciences 225, I18-130.

MASOVER, G. K. \& HAYFlick, L. (I974). Dialysis culture of T-strain mycoplasmas. Journal of Bacteriology II8, 46-52.

MAsover, G. K., Benson, J. R. \& HAyflick, L. (1974). Growth of T-strain mycoplasmas in medium without added urea: effect of trace amounts of urea and of a urease inhibitor. Journal of Bacteriology Ir7, $765-774$.

MAsOver, G. K., SAWYER, J. E. \& HAYflick, L. (1976). Urea hydrolyzing activity of a T-strain mycoplasma: (Ureaplasma urealyticum). Journal of Bacteriology 125, 581-587.

Purcell, R. H., Taylor-Robinson, D., Wong, D. \& Chanock, R. M. (1966). Color test for the measurement of antibody to T-strain mycoplasmas. Journal of Bacteriology 92, 6-12.

REED, L. J. \& MUENCH, H. (1938). A simple method of estimating fifty percent endpoints. Journal of Hygiene 27, 493-497.

Seligson, D. \& Seligson, H. (I95I). A microdiffusion method for the determination of nitrogen liberated as ammonia. Journal of Laboratory and Clinical Medicine 38, 324-330.

ShePARD, M. C. (I973). Differential methods for identification of T-strain mycoplasmas based on demonstration of urease. Journal of Infectious Diseases 127 (suppl.), 522-525.

Shepard, M. C., Lunceford, C. D., Ford, D. K., Purcell, R. H., Taylor-Robinson, D., Razin, S. \& BLACK, F. T. (1974). Ureaplasma urealyticum gen. nov., sp. nov.; proposed nomenclature for human T (T-strain) mycoplasmas. International Journal of Systematic Bacteriology 24, 160-I7I. 